Abstracta Iranica Abstracta Iranica

Revue bibliographique pour le domaine irano-aryen

Volume 22 | 2001

Comptes rendus des publications de 1999

\title{
Lo Specchio Alessandrino. Traduzione dal persiano e introduzione di Angelo M. Piemontese, Rubbettino Editore, Soviera Mannelli, 1999, 188 p. (Coll. Medioevo Romanzo e Orientale, testi, 5).
}

\section{Charles-Henri de Fouchécour}

\section{OpenEdition}

Journals

Édition électronique

URL : http://journals.openedition.org/abstractairanica/36988

DOI : 10.4000/abstractairanica.36988

ISSN : 1961-960X

Éditeur :

CNRS (UMR 7528 Mondes iraniens et indiens), Éditions de l'IFRI

Édition imprimée

Date de publication : 15 mai 2001

ISSN : 0240-8910

\section{Référence électronique}

Charles-Henri de Fouchécour, «Lo Specchio Alessandrino. Traduzione dal persiano e introduzione di Angelo M. Piemontese, Rubbettino Editore, Soviera Mannelli, 1999, 188 p. (Coll. Medioevo Romanzo e Orientale, testi, 5). », Abstracta Iranica [En ligne], Volume 22 | 2001, document 460, mis en ligne le 17 février 2010, consulté le 13 octobre 2020. URL : http://journals.openedition.org/abstractairanica/ 36988 ; DOI : https://doi.org/10.4000/abstractairanica.36988

Ce document a été généré automatiquement le 13 octobre 2020

Tous droits réservés 


\title{
Lo Specchio Alessandrino. Traduzione dal persiano e introduzione di Angelo M. Piemontese, Rubbettino Editore, Soviera Mannelli, 1999, 188 p. (Coll. Medioevo Romanzo e Orientale, testi, 5).
}

\author{
Charles-Henri de Fouchécour
}

Première traduction en langue européenne de l'œuvre du 'Turco-indostano' Amīr Hosrow Dehlavī (649/1251-726/1325) consacrée au Roman d'Alexandre, Āyene-ye Eskandarī, «Le Miroir d'Alexandre ». Il s'agit du quatrième poème mațnavī de la Hamsa de ce poète de premier plan (voir Encyclopédie de l'Islam ², I, 1960, p. 457, Dictionnaire Universel des Littératures, I, 1994, p. 137). Le cinquième poème fut celui des Huit Paradis, dont A. Piemontese a fourni une importante traduction et une brillante étude (voir Abs. Ir., 20-21, n 618). Le Miroir d'Alexandre fut composé en 699/1299, au temps où 'Alā al-Dīn, sultan de la dynastie turque Khaldji, régnait à Dehli. Les pp. 5-28 forment une très riche présentation du roman d'Amīr Hुosrow. On y voit comment, autour de quatre thèmes essentiels (vie / mort, résurrection / famine, amitié / inimitié, mer / abîme), le roman est construit, pour montrer en Alexandre le cosmocrator, empereur des quatre Horizons (Rome, Afrique, Perse et Chine) et des quatre Éléments (mer, terre, feu et air). A. Piemontese s'attache à montrer comment Amīr Hosrow s'est fondé sur ses grands prédécesseurs, depuis Tabarī-Bal'amī, et s'en est démarqué. Traité d'art politique, d'éthique humaine et d'étologie animale, le Miroir d'Alexandre est une enquête sur l'agir exemplaire, scientifique et pratique, de l'Alexandre légendaire, roi légitime, puissant, juste et sage. Le parfait homo sapiens, en somme. L'un des thèmes majeurs de l'œuvre est la mer, spécialement l'exploration de l'abîme, qui a été spécialement étudié par l'A. (cf. c.r. $n^{\circ} 499$ ). Au-delà de la fine analyse d'une œuvre dont il montre toute l'originalité, il 
s'attache à mettre en valeur la qualité de son style et la grande variété de ses modes narratifs, insistant tout spécialement sur le frappant équilibre de la composition. Cette riche introduction permet ensuite au traducteur de sélectionner les grands épisodes vraiment originaux du Miroir pour sa traduction, comme l'épithalame de l'esclave, le cataclysme de la Grèce, le gouvernement de Platon, l'expédition océanique ou l'observation de l'abîme dans un submersible.

INDEX

Thèmes : 11.1.1. Littérature persane classique

\section{AUTEURS}

\section{CHARLES-HENRI DE FOUCHÉCOUR}

Sorbonne Nouvelle - Paris III 